Taxonomy and systematics

\title{
A new species of scorpion of the genus Centruroides (Scorpiones: Buthidae) from the state of Michoacán, Mexico
}

\author{
Una especie nueva de alacrán del género Centruroides (Scorpiones: Buthidae) \\ del estado de Michoacán, México
}

\author{
Ana F. Quijano-Ravell ${ }^{\mathrm{a}}$, Javier Ponce-Saavedra ${ }^{\mathrm{b}, *}$ \\ ${ }^{a}$ Programa Institucional de Doctorado en Ciencias Biológicas, Opción en Conservación y Manejo de Recursos Naturales, \\ Universidad Michoacana de San Nicolás de Hidalgo, Edificio R, Ciudad Universitaria, 58060 Morelia, Michoacán, Mexico \\ ${ }^{\mathrm{b}}$ Laboratorio de Entomología “Biol. Sócrates Cisneros Paz”, Facultad de Biología, Universidad Michoacana de San Nicolás de Hidalgo, \\ Edificio B-4, $2^{\text {do }}$ piso, Ciudad Universitaria, 58060 Morelia, Michoacán, Mexico \\ Received 30 April 2015; accepted 4 September 2015 \\ Available online 26 February 2016
}

\begin{abstract}
Centruroides ruana sp. nov. is described from Felipe Carrillo Puerto, from the Buenavista Municipality in the state of Michoacán, Mexico. The new species was compared with C. balsasensis Ponce-Saavedra \& Francke, 2004, C. infamatus Koch, 1844, and C. limpidus (Karsch, 1879), which are both morphologically its closest relatives and geographically proximate. The description includes the male holotype, with 7 male and 8 female paratypes. A supplementary morphometric analysis is also presented allowing to distinguish the 4 species.

All Rights Reserved (C) 2015 Universidad Nacional Autónoma de México, Instituto de Biología. This is an open access item distributed under the Creative Commons CC License BY-NC-ND 4.0.

Keywords: Buthidae; Morphology; Morphometric methods; Taxonomy

\section{Resumen}

Se describe Centruroides ruana sp. nov. de Felipe Carrillo Puerto, municipio de Buenavista en el estado de Michoacán, México. Se hace una comparación con las especies morfológica y geográficamente más cercanas: C. balsasensis Ponce-Saavedra y Francke, 2004, C. infamatus Koch, 1844 y C. limpidus (Karsch, 1879). La descripción incluye el macho holotipo, 7 machos y 8 hembras paratipos. Se presenta un análisis morfométrico que también permitió diferenciar las 4 especies.

Derechos Reservados (C) 2015 Universidad Nacional Autónoma de México, Instituto de Biología. Este es un artículo de acceso abierto distribuido bajo los términos de la Licencia Creative Commons CC BY-NC-ND 4.0.
\end{abstract}

Palabras clave: Buthidae; Morfología; Métodos morfométricos; Taxonomía

\section{Introduction}

The family Buthidae is the most speciose in the order Scorpiones. It currently includes 91 genera and 1,044 species worldwide (Ponce-Saavedra \& Francke, 2013a; Rein, 2015; Teruel, Kovarik, Baldazo-Monsivais, \& Hoferek, 2015). In

\footnotetext{
* Corresponding author.

E-mail address: ponce.javier0691@gmail.com (J. Ponce-Saavedra).

Peer Review under the responsibility of Universidad Nacional Autónoma de México.
}

Mexico, the family is represented by 2 genera: Centruroides Marx, 1890, with 42 species out of a total of 85 native to the American continent, and Chaneke Francke, Teruel and Santibañez-López, 2014, with 2 species (Francke, Teruel, \& Santibañez-López, 2014; Ponce-Saavedra \& Francke, 2013a; Rein, 2015; Teruel et al., 2015).

Centruroides occurs continuously across the American continent from central USA through western South America, including most of the archipelagos associated with continents, such as the West Indies and Galapagos. It is the most common and widespread scorpion genus in Mexico, and the only one that 
Table 1

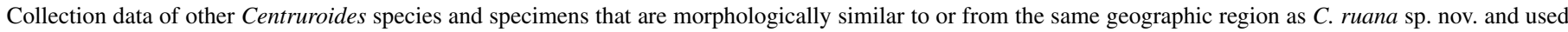
for the morphological and morphometric analyses.

\begin{tabular}{|c|c|c|c|}
\hline \multirow[t]{2}{*}{ Species } & \multirow[t]{2}{*}{ Locality/geographical coordinates } & \multicolumn{2}{|c|}{ Number of individuals } \\
\hline & & $\sigma^{x} \sigma^{x}$ & 우우 \\
\hline Centruroides balsasensis & Arúa, Huetamo Michoacán, Mexico/18.540278N, 100.926389W & 4 & 3 \\
\hline Centruroides balsasensis & Churumuco, Michoacán, Mexico/18.660833N, 101.646111W & 3 & 4 \\
\hline Centruroides infamatus & León, Guanajuato, Mexico/21.017222N, 101.628889W & 3 & 2 \\
\hline Centruroides infamatus & Zumpimito, Uruapan, Michoacán, Mexico/21.125000N, 101.030278W & 4 & 4 \\
\hline Centruroides limpidus & Arcelia, Guerrero, Mexico/18.283056N, 100.266667W & 7 & 7 \\
\hline Centruroides tecomanus & Faro de Bucerías, Aquila, Michoacán, Mexico/18.335833N, 103.500833W & 7 & 6 \\
\hline
\end{tabular}

has medical importance due to the toxicity of several species (Fet \& Lowe, 2000). Recent contributions (Ponce-Saavedra \& Francke, 2013a,b; Ponce-Saavedra, Martínez-Rodríguez, \& Quijano-Ravell, 2015) list 7 species of Centruroides for the state of Michoacán, with well-defined geographical distributions: (1) Balsas Basin (locally known as "tierra caliente", a vernacular term that literally means "hot lands"): Centruroides balsasensis Ponce-Saavedra \& Francke, 2004, Centruroides bertholdii (Thorell, 1876), Centruroides infamatus (C. L. Koch, 1844), and Centruroides limpidus (Karsch, 1879). (2) Pacific coastal plain: Centruroides nigrescens (Pocock, 1898) and Centruroides tecomanus Hoffmann, 1932. (3) Transverse Volcanic Belt: Centruroides ornatus Pocock, 1902.

The Balsas Basin is a unique biogeographical region of Mexico evidenced by high levels of plant and animal endemism. In the case of scorpions, 2 genera are endemic: Киагари Francke and Ponce-Saavedra, 2010 and Balsateres González-Santillán and Prendini, 2013. Also, 6 species are restricted to this basin: the diplocentrids Diplocentrus churumuco Francke and PonceSaavedra, 2004 and Kolotl poncei (Francke and Quijano-Ravell, 2009); the vaejovids Balsateres cisnerosi (Ponce-Saavedra and Sissom, 2004), Konetontli kuarapu (Francke and PonceSaavedra, 2006), and Kuarapu purhepecha Francke and Ponce-Saavedra, 2010; and the buthid Centruroides balsasensis Ponce-Saavedra \& Francke, 2004.

The new species described herein represents yet another case of an endemic scorpion from the Balsas Basin and increases the number of Centruroides known to occur in Michoacán and the Balsas Basin to 8 and 5, respectively.

\section{Materials and methods}

Scorpions were collected during daytime by intensive direct sampling, i.e., turning rocks and other objects on the ground, peeling bark, and searching inside soil cracks and crevices. All specimens were preserved in $96 \%$ ethanol. They were deposited in the following collections: holotype and some paratypes at the Colección Nacional de Arácnidos, Instituto de Biología, Universidad Nacional Autónoma de México, D.F., Mexico (CNAN), and paratypes at the Colección Aracnológica del Laboratorio de Entomología "Biol. Sócrates Cisneros Paz", Facultad de Biología, Universidad Michoacana de San Nicolás de Hidalgo, Morelia, Michoacán, Mexico (CAFBUM).
The specimens were studied, measured and photographed using a Zeiss Stemi DV4 stereomicroscope, equipped with a $0.1 \mathrm{~mm}$ ocular micrometer. High-resolution digital photographs were taken using either white or UV light and then slightly processed with Adobe Photoshop CS5, only to remove background and to optimize brightness and contrast parameters for printing. Measurements and pectinal tooth counts were taken to analyze morphometric and meristic variation of the species. All measurements are reported in millimeters $(\mathrm{mm})$. The description was made according to nomenclature and measurements of Stahnke (1970), except for the description of carination of the chelae of pedipalp, which was made according to Acosta, Candido, Buckup, and Brescovit (2008) and the carination of metasomal segments, which followed Francke (1977).

A direct morphological comparison was made among adults of similar species from samples taken in different localities of Mexico, including material coming from the type locality of C. balsasensis and specimens of C. limpidus, from Arcelia, Guerrero, and C. infamatus, from León, Guanajuato and from Uruapan, Michoacán. These 3 species are morphologically the most similar to the new species. Further, samples of $C$. tecomanus from Faro de Bucerías, Aquila, Michoacán, were also included in the comparison because this species can also confused if the color pattern of the carapace is not considered (Table 1).

To determine which variables were best to diagnose the new species, a morphometric comparison was conducted based on 54 variables: 28 direct measurements, 25 calculated proportional ratios, and pectinal tooth counts (Table 2). Some of these ratios have been confirmed elsewhere as useful in other species of Centruroides (Ponce-Saavedra \& Francke, 2004, 2009, 2011a, 2011b; Ponce-Saavedra, Francke, CanoCamacho, \& Hernández-Calderón, 2009; Santibáñez-López \& Ponce-Saavedra, 2009).

The matrix generated was separated by sex, taking into account the well-known sexual dimorphism in most species of the genus (Hoffmann, 1932; Ozkan, Adiguzel, \& Kar, 2006; Ponce-Saavedra \& Francke, 2011a,b). A Multiple Correlation Analysis was run on each matrix, searching for both redundant (correlation $\geq 80 \%$ ) and outlier data. In addition, a Principal Component Analysis (PCA) was applied to the data matrices, in order to detect the most informative variables to characterize species, e.g., a "noise-reduction filter" (unexplained 
Table 2

Measurements (in $\mathrm{mm}$ ) and proportions of holotype and 7 paratypes of Centruroides ruana sp. nov.

\begin{tabular}{|c|c|c|c|c|c|c|c|c|}
\hline \multirow[t]{2}{*}{ Measurements } & \multicolumn{4}{|c|}{ Males } & \multicolumn{4}{|c|}{ Females } \\
\hline & Holotype & MP1 & MP2 & MP3 & FP1 & FP2 & FP3 & FP4 \\
\hline Carapace length & 6.40 & 6.40 & 6.00 & 6.40 & 6.60 & 6.40 & 6.00 & 6.00 \\
\hline Mesosoma length, including tergite VII & 18.20 & 18.60 & 17.60 & 18.20 & 18.20 & 18.80 & 19.80 & 17.80 \\
\hline Tergite VII length & 5.80 & 5.60 & 5.60 & 5.60 & 4.60 & 4.80 & 4.80 & 4.60 \\
\hline Pectinal tooth count & $24-24$ & $26-26$ & $24-24$ & $25-25$ & $25-25$ & $22-22$ & $23-23$ & $24-24$ \\
\hline Metasomal segment I length & 6.00 & 6.00 & 5.80 & 6.00 & 4.60 & 4.60 & 4.20 & 4.20 \\
\hline Metasomal segment II length & 7.20 & 7.40 & 7.00 & 7.40 & 5.40 & 5.40 & 5.00 & 5.00 \\
\hline Metasomal segment III length & 8.00 & 8.00 & 7.80 & 8.00 & 5.80 & 5.80 & 5.40 & 5.40 \\
\hline Metasomal segment IV length & 8.60 & 8.40 & 8.40 & 8.60 & 6.40 & 6.20 & 5.80 & 5.80 \\
\hline Metasomal segment V length & 9.60 & 9.40 & 9.20 & 9.60 & 7.40 & 7.20 & 6.60 & 6.60 \\
\hline Metasomal segment I width & 3.00 & 3.20 & 2.60 & 3.00 & 3.20 & 3.20 & 3.20 & 3.20 \\
\hline Metasomal segment II width & 2.80 & 3.00 & 2.60 & 2.80 & 3.00 & 3.00 & 3.00 & 3.00 \\
\hline Metasomal segment III width & 2.80 & 3.00 & 2.60 & 2.80 & 3.00 & 3.00 & 3.00 & 3.00 \\
\hline Metasomal segment IV width & 2.80 & 3.00 & 2.40 & 2.80 & 3.00 & 3.00 & 3.00 & 2.80 \\
\hline Metasomal segment V width & 2.80 & 3.00 & 2.40 & 2.80 & 2.80 & 2.80 & 2.80 & 2.80 \\
\hline Vesicle length & 4.20 & 4.20 & 4.00 & 4.20 & 3.60 & 3.60 & 3.20 & 3.20 \\
\hline Vesicle width & 2.20 & 2.20 & 2.20 & 2.20 & 2.20 & 2.20 & 2.00 & 2.00 \\
\hline Vesicle depth & 2.20 & 2.20 & 1.80 & 2.20 & 2.20 & 2.00 & 2.00 & 2.00 \\
\hline Aculeus length & 2.40 & 2.40 & 2.20 & 2.40 & 2.80 & 2.60 & 2.60 & 2.60 \\
\hline Pedipalp femur length & 6.60 & 6.60 & 6.20 & 6.60 & 5.20 & 6.00 & 5.60 & 5.60 \\
\hline Pedipalp femur width & 1.60 & 1.60 & 1.40 & 1.60 & 1.50 & 1.60 & 1.60 & 1.60 \\
\hline Pedipalp patella length & 7.20 & 7.20 & 6.80 & 7.20 & 5.80 & 6.80 & 6.20 & 6.40 \\
\hline Pedipalp patella width & 2.20 & 2.20 & 2.00 & 2.20 & 2.00 & 2.20 & 2.20 & 2.20 \\
\hline Pedipalp hand length & 5.20 & 5.00 & 5.00 & 5.20 & 3.80 & 4.80 & 4.40 & 4.60 \\
\hline Pedipalp hand width & 2.40 & 2.40 & 2.10 & 2.40 & 2.40 & 2.40 & 2.20 & 2.40 \\
\hline Pedipalp hand depth & 2.40 & 2.40 & 2.20 & 2.40 & 2.40 & 2.40 & 2.20 & 2.40 \\
\hline Pedipalp fixed finger length & 5.80 & 5.60 & 5.40 & 5.60 & 4.80 & 5.80 & 5.40 & 5.60 \\
\hline Pedipalp movable finger length & 6.80 & 6.60 & 6.60 & 6.60 & 5.60 & 7.00 & 6.40 & 6.40 \\
\hline Basal pectinal plate length & 0.80 & 0.70 & 0.60 & 0.80 & 0.80 & 0.80 & 0.80 & 0.80 \\
\hline Basal pectinal plate width & 1.20 & 1.20 & 1.20 & 1.20 & 1.40 & 1.50 & 1.50 & 1.60 \\
\hline Basal pectinal plate length/width ratio & 0.67 & 0.58 & 0.50 & 0.67 & 0.57 & 0.53 & 0.53 & 0.50 \\
\hline Pedipalp hand/patella width ratio & 1.09 & 1.09 & 1.05 & 1.09 & 1.20 & 1.09 & 1.00 & 1.09 \\
\hline Pedipalp hand/telson vesicle width ratio & 1.09 & 1.09 & 1.05 & 1.09 & 1.09 & 1.09 & 1.10 & 1.20 \\
\hline Pedipalp hand width/telson vesicle length ratio & 0.57 & 0.57 & 0.53 & 0.57 & 0.67 & 0.67 & 0.69 & 0.75 \\
\hline Carapace/pedipalp movable finger length ratio & 0.94 & 0.97 & 1.11 & 0.97 & 1.18 & 0.91 & 0.94 & 0.94 \\
\hline Metasomal segment V/pedipalp movable finger length ratio & 1.41 & 1.42 & 1.70 & 1.45 & 1.32 & 1.03 & 1.03 & 1.03 \\
\hline Metasomal segment V/III length ratio & 1.20 & 1.18 & 1.18 & 1.20 & 1.28 & 1.24 & 1.22 & 1.22 \\
\hline Metasomal segment $\mathrm{V} /$ pedipalp hand length ratio & 1.85 & 1.88 & 1.84 & 1.85 & 1.95 & 1.50 & 1.50 & 1.43 \\
\hline Telson vesicle length/depth ratio & 1.91 & 1.91 & 2.22 & 1.91 & 1.64 & 1.80 & 1.60 & 1.60 \\
\hline Metasomal segment V/IV length ratio & 1.12 & 1.12 & 1.10 & 1.12 & 1.16 & 1.16 & 1.14 & 1.14 \\
\hline Metasomal segment V/telson vesicle length ratio & 2.29 & 2.24 & 2.30 & 2.29 & 2.06 & 2.00 & 2.06 & 2.06 \\
\hline Metasomal segment V/I length ratio & 1.60 & 1.57 & 1.59 & 1.60 & 1.61 & 1.57 & 1.57 & 1.57 \\
\hline Metasomal segment $\mathrm{V} /$ pedipalp hand length ratio & 1.15 & 1.20 & 1.16 & 1.15 & 1.21 & 0.96 & 0.95 & 0.91 \\
\hline Metasomal segment V/carapace length ratio & 1.50 & 1.47 & 1.53 & 1.50 & 1.12 & 1.13 & 1.10 & 1.10 \\
\hline Pedipalp patella/pedipalp hand length ratio & 1.38 & 1.44 & 1.36 & 1.38 & 1.53 & 1.42 & 1.41 & 1.39 \\
\hline Metasomal segment I length/width ratio & 2.00 & 1.88 & 2.23 & 2.00 & 1.44 & 1.44 & 1.31 & 1.31 \\
\hline Metasomal segment II length/width ratio & 2.57 & 2.47 & 2.69 & 2.64 & 1.80 & 1.80 & 1.67 & 1.67 \\
\hline Metasomal segment III length/width ratio & 2.86 & 2.67 & 3.00 & 2.86 & 1.93 & 1.93 & 1.80 & 1.80 \\
\hline Metasomal segment IV length/width ratio & 3.07 & 2.80 & 3.50 & 3.07 & 2.13 & 2.07 & 1.93 & 2.07 \\
\hline Metasomal segment V length/width ratio & 3.43 & 3.13 & 3.83 & 3.43 & 2.64 & 2.57 & 2.36 & 2.36 \\
\hline Pedipalp femur length/width ratio & 4.13 & 4.13 & 4.43 & 4.13 & 3.47 & 3.75 & 3.50 & 3.50 \\
\hline Pedipalp patella length/width ratio & 3.27 & 3.27 & 3.40 & 3.27 & 2.90 & 3.09 & 2.82 & 2.91 \\
\hline Pedipalp hand length/width ratio & 2.17 & 2.08 & 2.38 & 2.17 & 1.58 & 2.00 & 2.00 & 1.92 \\
\hline Pedipalp movable finger/pedipalp hand length ratio & 1.12 & 1.12 & 1.08 & 1.08 & 1.26 & 1.21 & 1.23 & 1.22 \\
\hline Pedipalp fixed finger/pedipalp hand length ratio & 1.31 & 1.32 & 1.32 & 1.27 & 1.47 & 1.46 & 1.45 & 1.39 \\
\hline
\end{tabular}

Abbreviations: MP, male paratype; FP, female paratype.

variation elimination). A Cluster Analysis (CA) and a canonical discriminant analysis were used to assess the adequacy of the selected variables to separate the species. All statistical tests were performed using JMP software, version 6.0 (2005).

\section{Description}

Family Buthidae C. L. Koch, 1837

Genus Centruroides Marx, 1890 
Table 3

Matrix with thirteen variables useful for multivariate distinction of males of Centruroides ruana sp. nov from closely related or geographically proximate species.

\begin{tabular}{|c|c|c|c|c|c|c|c|}
\hline \multirow{2}{*}{$\begin{array}{l}\text { Males } \\
\text { Variable }\end{array}$} & \multicolumn{7}{|c|}{ Mean $( \pm \mathrm{SD})$} \\
\hline & C. ruana sp. nov. & C. infamatus & C. balsasensis & C. limpidus & C. tecomanus & Value $X^{2}$ & Prob. \\
\hline Pectinal tooth count & 24-26 (mode 25$)$ & $21-24($ mode $=23)$ & $25-28($ mode $=25)$ & $23-25($ mode $=24)$ & $20-24($ mode $=23)$ & & \\
\hline $\begin{array}{l}\text { Metasomal segment I } \\
\text { length/width ratio }\end{array}$ & $1.97( \pm 0.07) \mathrm{ABC}$ & $2.09( \pm 0.12) \mathrm{AB}$ & $2.14( \pm 0.17) \mathrm{A}$ & $1.87( \pm 0.06) \mathrm{C}$ & $1.92( \pm 0.07) \mathrm{BC}$ & 16.594 & 0.0023 \\
\hline $\begin{array}{l}\text { Metasomal segment II } \\
\text { length/width ratio }\end{array}$ & $2.52( \pm 0.07) \mathrm{B}$ & $2.65( \pm 0.19) \mathrm{AB}$ & $2.90( \pm 0.23) \mathrm{A}$ & $2.41( \pm 0.12) \mathrm{B}$ & $2.41( \pm 0.10) \mathrm{B}$ & 18.11 & 0.0012 \\
\hline $\begin{array}{l}\text { Metasomal segment III } \\
\text { length/width ratio }\end{array}$ & $2.77( \pm 0.16) \mathrm{BC}$ & $2.991( \pm 0.18) \mathrm{B}$ & $3.22( \pm 0.26) \mathrm{A}$ & $2.66( \pm 0.12) \mathrm{BC}$ & $2.56( \pm 0.12) \mathrm{C}$ & 20.492 & 0.0004 \\
\hline $\begin{array}{l}\text { Pedipalp patella length/width } \\
\text { ratio }\end{array}$ & $3.21( \pm 0.09) \mathrm{A}$ & $3.13( \pm 0.17) \mathrm{AB}$ & $2.99( \pm 0.08) \mathrm{BC}$ & $2.91( \pm 0.05) \mathrm{C}$ & $2.69( \pm 0.09) \mathrm{D}$ & 24.335 & $<0.0001$ \\
\hline $\begin{array}{l}\text { Carapace/pedipalp movable } \\
\text { finger length ratio }\end{array}$ & $0.93( \pm 0.01) \mathrm{A}$ & $0.86( \pm 0.01) \mathrm{B}$ & $0.86( \pm 0.03) \mathrm{B}$ & $0.88( \pm 0.02) \mathrm{B}$ & $0.89( \pm 0.04) \mathrm{AB}$ & 14.276 & 0.0065 \\
\hline $\begin{array}{l}\text { Metasomal segment } \\
\text { I/pedipalp hand length ratio }\end{array}$ & $1.13( \pm 0.04) \mathrm{A}$ & $1.18( \pm 0.03) \mathrm{A}$ & $0.59( \pm 0.01) \mathrm{B}$ & $0.55( \pm 0.02) \mathrm{B}$ & $0.58( \pm 0.05) \mathrm{B}$ & 26.942 & $<0.0001$ \\
\hline $\begin{array}{l}\text { Metasomal segment } \\
\text { V/pedipalp movable finger } \\
\text { length ratio }\end{array}$ & $1.36( \pm 0.05) \mathrm{A}$ & $1.40( \pm 0.02) \mathrm{A}$ & $1.37( \pm 0.06) \mathrm{A}$ & $1.27( \pm 0.03) \mathrm{B}$ & $1.35( \pm 0.06) \mathrm{B}$ & 14.354 & 0.0062 \\
\hline $\begin{array}{l}\text { Metasomal segment II/I } \\
\text { length ratio }\end{array}$ & $1.58( \pm 0.06) \mathrm{A}$ & $1.51( \pm 0.02) \mathrm{B}$ & $1.51( \pm 0.05) \mathrm{AB}$ & $1.46( \pm 0.03) \mathrm{B}$ & $1.46( \pm 0.03) \mathrm{B}$ & 17.436 & 0.0016 \\
\hline $\begin{array}{l}\text { Metasomal segment IV/telson } \\
\text { vesicle length ratio }\end{array}$ & $2.04( \pm 0.06) \mathrm{A}$ & $1.88( \pm 0.10) \mathrm{B}$ & $2.08( \pm 0.04) \mathrm{A}$ & $1.86( \pm 0.05) \mathrm{B}$ & $1.97( \pm 0.06) \mathrm{AB}$ & 21.144 & 0.0003 \\
\hline $\begin{array}{l}\text { Metasomal segment V/telson } \\
\text { vesicle length ratio }\end{array}$ & $2.27( \pm 0.08) \mathrm{AB}$ & $2.11( \pm 0.09) \mathrm{C}$ & $2.32( \pm 0.09) \mathrm{A}$ & $2.07( \pm 0.06) \mathrm{C}$ & $2.15( \pm 0.06) \mathrm{BC}$ & 21.119 & 0.0003 \\
\hline $\begin{array}{l}\text { Metasomal segment } \\
\text { V/pedipalp hand length } \\
\text { ratio }\end{array}$ & $1.79( \pm 0.08) \mathrm{A}$ & $1.79( \pm 0.04) \mathrm{A}$ & $0.90( \pm 0.02) \mathrm{B}$ & $0.81( \pm 0.02) \mathrm{B}$ & $0.85( \pm 0.07) \mathrm{B}$ & 28.718 & $<0.0001$ \\
\hline $\begin{array}{l}\text { Metasomal segment } \\
\text { V/pedipalp fixed finger } \\
\text { length ratio }\end{array}$ & $1.62( \pm 0.05) \mathrm{A}$ & $1.65( \pm 0.06) \mathrm{A}$ & $1.56( \pm 0.10) \mathrm{AB}$ & $1.49( \pm 0.06) \mathrm{B}$ & $1.55( \pm 0.06) \mathrm{B}$ & 12.306 & 0.0152 \\
\hline
\end{tabular}

\section{Diagnosis}

This genus can be distinguished from all other members of Buthidae by the following combination of characters: (a) pedipalp fingers with 7-10 principal rows of denticles which are only slightly overlapping, oblique and flanked by external and internal supernumerary denticles on each side (missing in first and second instar immatures); (b) absence of stridulatory organ on sternite III and pectines; adult males with metasomal segments longer and narrower than females (Armas, 2009).
Centruroides ruana sp. nov.

(Morphometric data: Tables 2 and 3; Figs. 1-3 and 6-8)

\section{Diagnosis}

The species is distinguished by the combination of the following characters: Scorpions of medium to moderately large adult size (including telson) for the genus. C. ruana sp. nov. is a typical "striped scorpion", basically yellow to ochre, paler ventrally, with 2 dorsal longitudinal blackish stripes on the mesosoma,
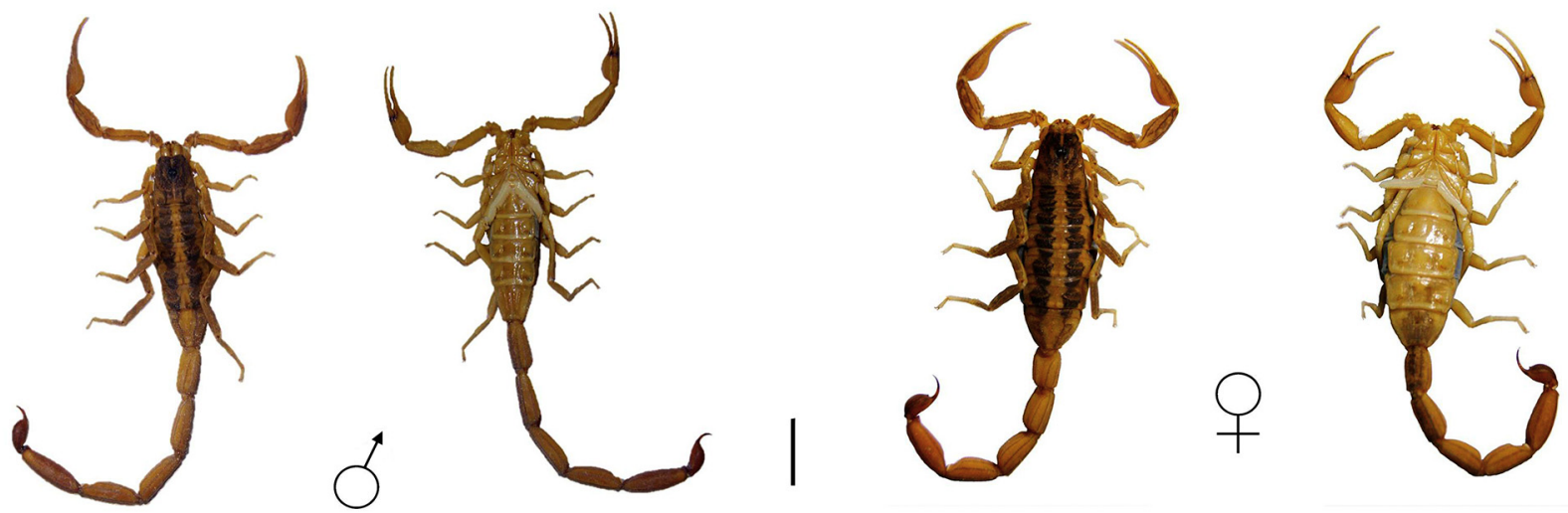

Figure 1. Habitus of dorsal and ventral views of holotype male and paratype female of Centruroides ruana sp. nov. Bars = $10 \mathrm{~mm}$. 
a

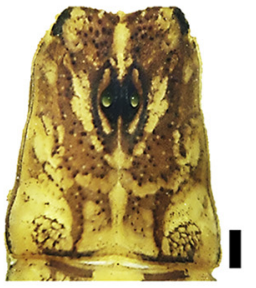

C

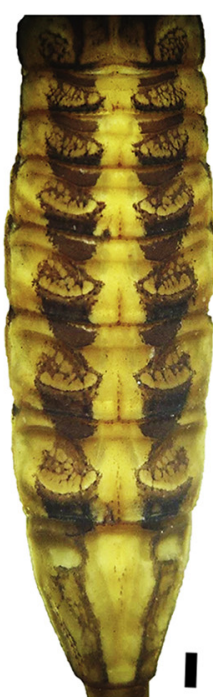

b

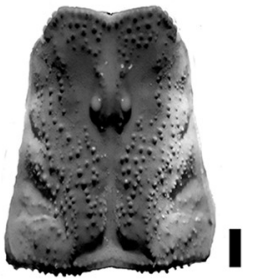

d

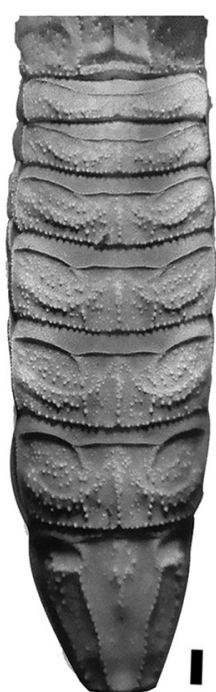

e

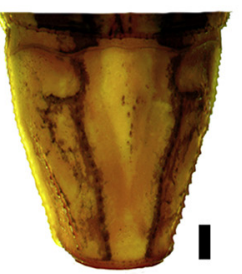

f

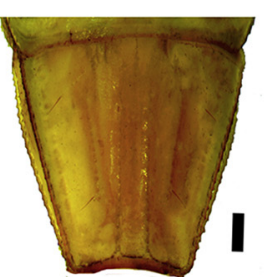

g

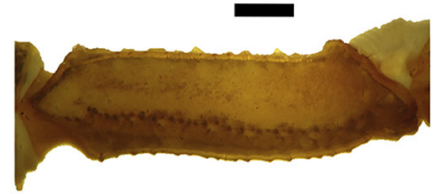

h

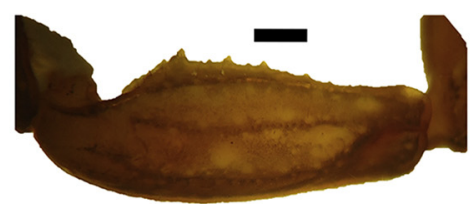

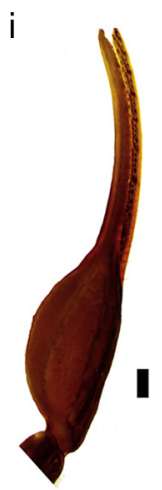

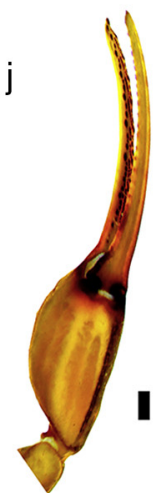

Figure 2. Adult male paratype of Centruroides ruana sp. nov.: (a and b) carapace; (c and d) mesosoma dorsal; (e) tergite VII; (f) sternite VII; (g) pedipalp femur dorsal; (h) pedipalp patella dorsal; (i) pedipalp chela, dorsoexternal view; (j) pedipalp chela ventrointernal view. Notes: photographs (a) and (b) were taken under UV light to show granulation. Bars $=1 \mathrm{~mm}$.

a

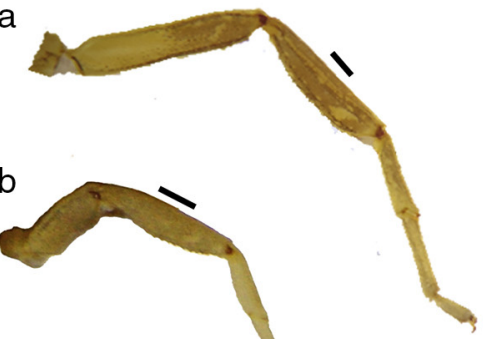

e

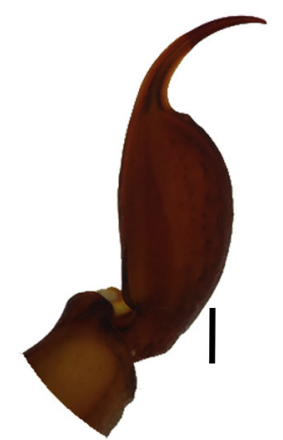

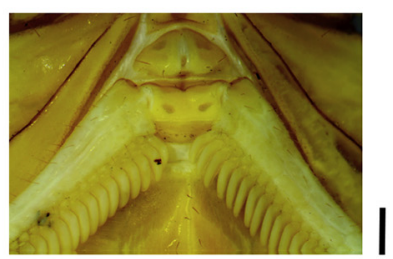
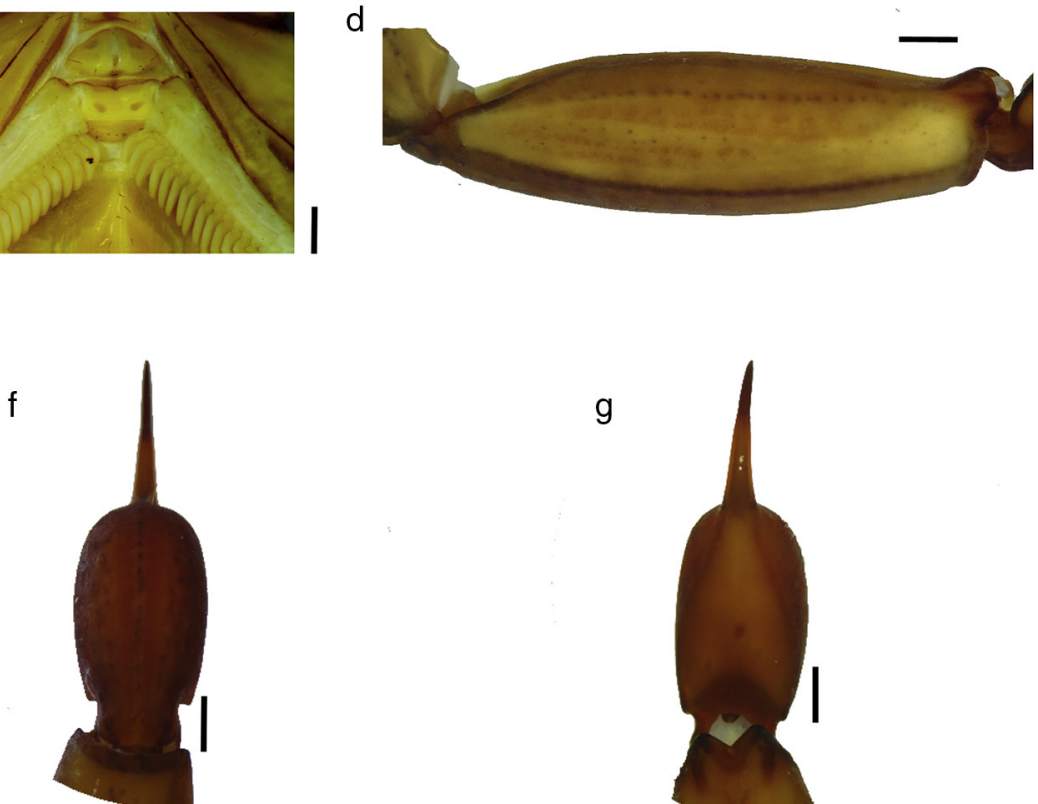

g

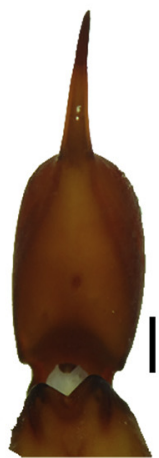

Figure 3. Adult male paratype of Centruroides ruana sp. nov.: (a) pigmentation leg IV; (b) pigmentation leg I; (c) basal pectinal plate; (d) metasomal segment V lateral; (e) telson lateral view; (f) telson ventral view; (g) telson dorsal view. Bars $=1 \mathrm{~mm}$. 


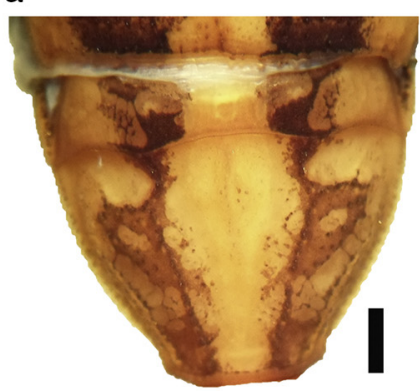

d

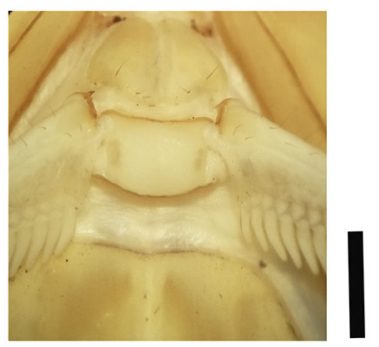

b

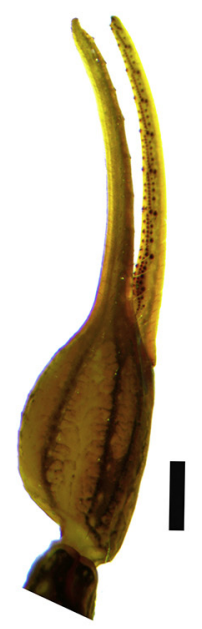

C

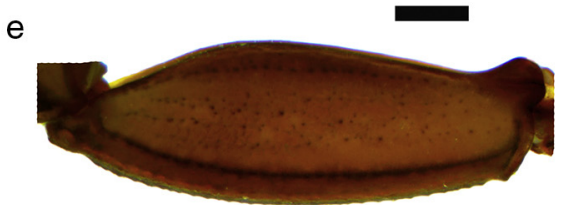

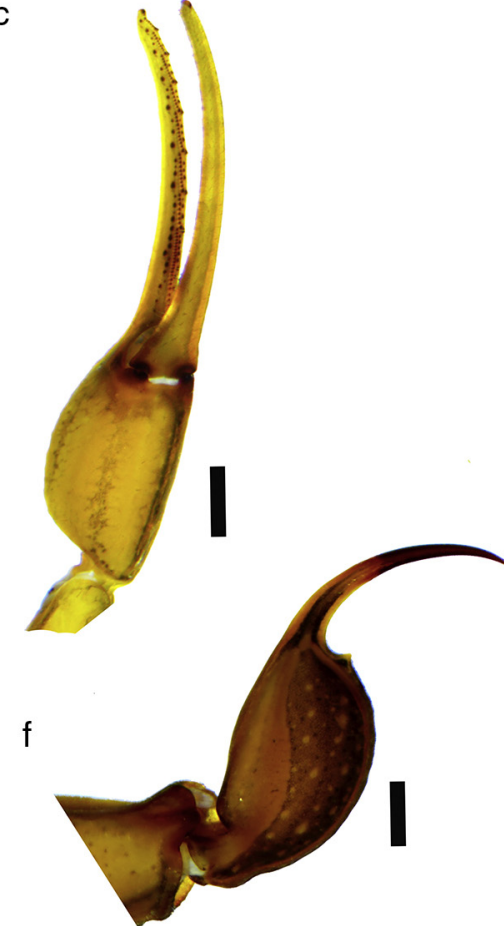

Figure 4. Sexual dimorphism in females Centruroides ruana sp. nov.: (a) tergite VII; (b) pedipalp chela dorsal view; (c) pedipalp chela ventral view; (d) basal pectinal plate; (e) metasomal segment $\mathrm{V}$, lateral view; (f) telson, lateral view. Bars $=1 \mathrm{~mm}$.

separated by a slightly wider pale stripe. Anterior median area of the carapace strongly pigmented in the anterior half except in the anterior median furrow and 2 areas above the lateral central furrow; the rear half area is slightly dark pigmented on both sides of the posterior median furrow and on the posterior lateral carinae which is more intense; intercarinal surface with dense and welldefined granules. Pedipalps moderately elongated; hand evenly oval and moderately incrassate. Basal plate of pectines in males is rectangular with the anterior notch $\mathrm{V}$-shaped, anterior margin slightly concave and lobulated, and posterior margin straight, in females the anterior margin is only slightly notched medially and with posterior margin rounded. Pectinal tooth counts $24-26$ (mode $25 ; n=14$ in males) vs. $22-25$ (mode $23 ; n=14$ ) in females. Metasoma with dorsolateral, lateral, supramedian and inframedian carinae well developed and serrated; vesicle slightly elongated. Sexual dimorphism evident, females with pedipalps shorter, less slender and more strongly carinate, bulkier hand, metasoma more strongly carinate and with shorter segment V, telson vesicle shorter and rounder, with a stronger subaculear tubercle.

\section{Description of the holotype male (CNAN-T0874)}

Coloration. A typical "striped scorpion", basically yellow, paler ventrally (Fig. 1). Anterior median area of the carapace is heavily pigmented, except for the median furrow and 2 lateral patches that extend from the sides of ocular tubercle through the lateral eyes (Fig. 2a). Posterior median area is slightly pigmented on both sides of the median furrow and darker on posterior lateral carinae. Median furrow immaculate, connected to a pale transverse area from posterior margin through median lateral carinae. Median eyes surrounded by a pattern of subtle spots, with a heavily pigmented margin. Lateral margins pale immaculate. The area around lateral eyes is very dark, with a pigmented stripe remarked by pale stripes on each side; the pigmented stripe becomes wider toward its posterior median part (Fig. 2a). Ocular tubercle intensely infuscate (Fig. 2a). Pedipalp: femur diffusely infuscate dorsally, becoming darker medially and distally (Fig. 2g). Patella diffusely infuscate dorsally, darker over carinae (Fig. 2h); chelae slightly darker but without defined pattern, except for heavily infuscate carinae (Fig. $2 \mathrm{i}$ and $\mathrm{j}$ ). Legs: irregularly pigmented, including femur, patella and tibiae (Fig. 3e-g). Legs I and II darker on distal area of patella near the articulation with tibiae and diffusely pigmented to immaculate on the rest. Femur, patella and tibiae of legs III-IV darker and becoming weaker on metatarsus (Fig. 3a and b). Mesosoma: dorsally with 2 longitudinal blackish stripes, separated by a slightly wider pale stripe. Each dark stripe is composed of a well-defined, large and concave spot over the postergite, which gradually becomes diffuse as a transversely oriented reticulate pattern through the pretergite, where it then fuses into another smaller, convex spot located just on the edge of tergites I-VI; the dark stripes gradually become diffuse also through tergite VII (Fig. 2c and e). Median longitudinal carena pigmented on all tergites (Fig. 2c). The blotches of the mesosomal dark bands consist of large spots in the postergite, concave toward the pretergite, which has a smaller convex spot. Both spots are interconnected with reticulated pigmentation. On pretergites II-III, every blackish spot looks like a horizontal stripe slightly inclined to the center of the tergite (Fig. 2c) and becomes somewhat crescent-shaped on postergite VII (Fig. 2c and e). Pigmented spots are surrounded by small to medium sized dots (Fig. $2 \mathrm{c}$ and e). Sternite VII slightly pigmented on median carinae (Fig. 2f). Metasoma: 


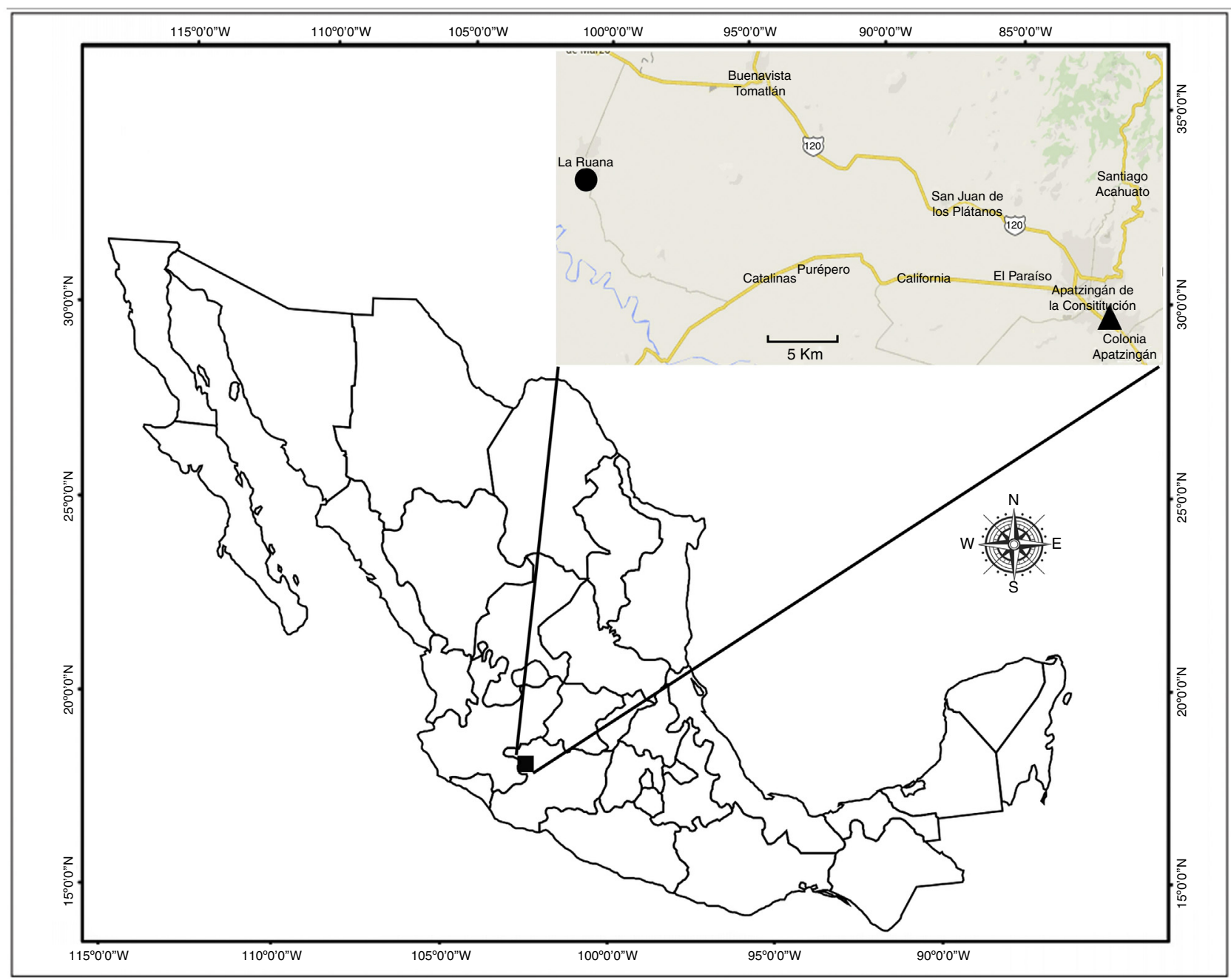

Figure 5. Known geographical distribution of Centruroides ruana sp. nov.: type-locality $(\bullet)$ and Apatzingán $(\triangle)$, Michoacán, Mexico. Modified from Google Maps.

dorsally immaculate, ventrally heavily infuscate over ventrolateral and ventral submedian carinae on I-IV and diffusely spotted on space between ventral submedian and ventrolateral carinae on segments I-III, weaker on IV, and immaculate on V (Figs. 3d and 6.11). Vesicle ochre-yellow; dorsally immaculate; ventrally and laterally with 1 median and 2 lateral infuscate stripes, separated by thin immaculate bands distally to the area around the subaculear tubercle, where spotted pattern becomes diffuse and with yellowish dots (Fig. 3e-g). Aculeus infuscate throughout, with distal half conspicuously darkened.

Carapace. Anterior margin concave, with weakly crenulate edge. Lateral areas feebly granulose to smooth, margins weakly crenulate (Fig. 2a and b). Ocular tubercle smooth, surrounded by small to medium-sized granules on pigmented areas, more developed behind median and lateral eyes (Fig. 2b). Posterior margin straight, with a shallow median indentation or notch, laterally with medium-sized granules (Fig. 2a and b).

Pedipalps. Moderately elongated (length/width ratio of femur and patella $=0.92$ ). All carinae weakly to moderately granulose
(Fig. 2g-j). Intercarinal spaces finely granulose on femur and patella coriaceous on chela (Fig. $2 \mathrm{~g}-\mathrm{j}$ ). Chela of pedipalps are granular with well-defined granules. Hand evenly oval and moderately incrassate (width hand/width patella ratio $=1.09$; length/width hand ratio $=2.16$ ) (for measurements see Table 2) (Fig. 2i and j). Digital carena moderate and smooth (Fig. 2i); ventroexternal and ventrointernal carinae strong and smooth (Fig. 2j). Fingers long, slender and evenly curved (Fig. 2i and $\mathrm{j}$ ), with 8 principal rows of denticles flanked by supernumerary denticles on each side, and with an apical subrow of 5 denticles.

Mesosoma. Tergites with strong median longitudinal carinae (Fig. 2d); submedian and lateral carinae on VII strong and serrate (Fig. 2e and f). All pigmented areas are covered by small to medium-sized granules, as in carapace (Fig. 2c and d). Sternite VII with media carinae slightly developed but complete (Fig. 2f).

Pectines. Tooth count 24/24. Basal plate of pectines in males is rectangular with the anterior notch V-shaped, anterior margin slightly concave and lobulated, and posterior margin straight (Table 2; Fig. 3c). 


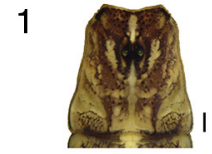

6
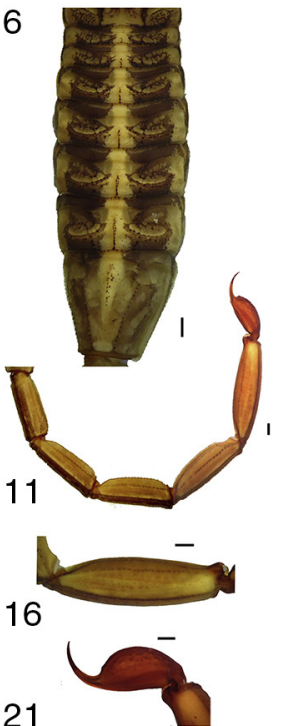

2

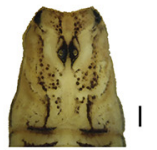

$$
7
$$

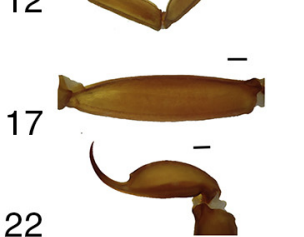

3

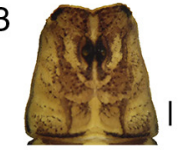

8

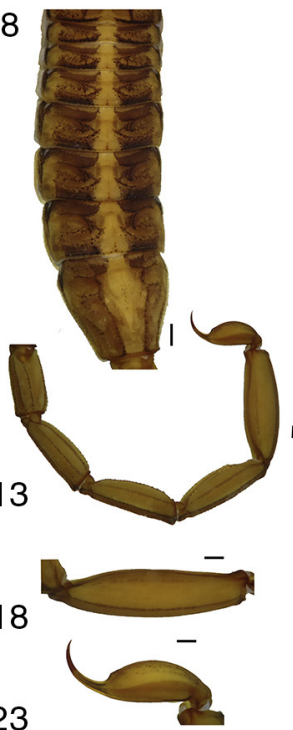

4

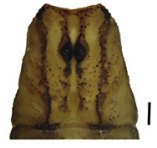

9
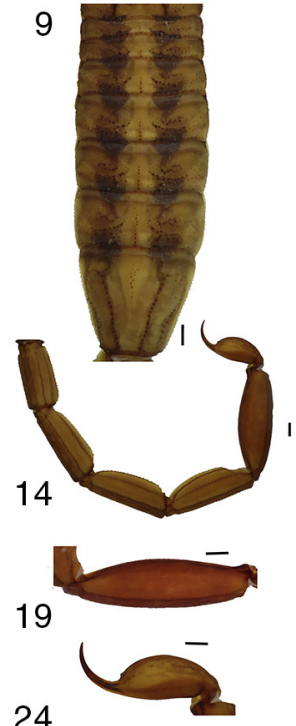

5
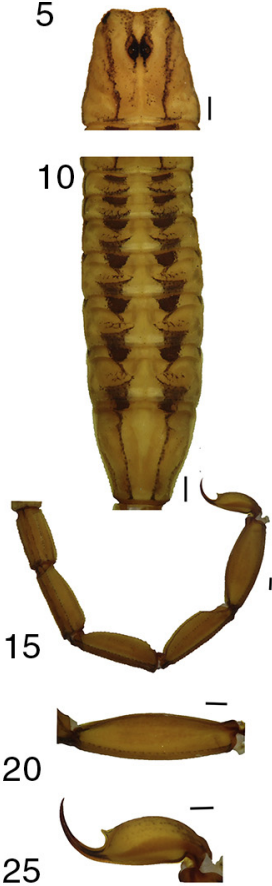

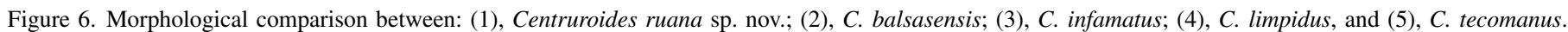

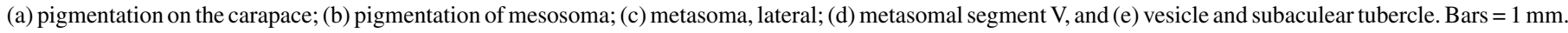

Metasoma. Moderately elongated and not incrassate distally (Figs. 3d and 6.11). Segments I-IV with the following carination: dorsal laterals, lateral supramedians and lateral inframedians (on I only) well developed, denticulate, the dorsal lateral carinae become gradually stronger distally on each segment; ventral laterals and ventral submedians well developed, finely serrate, but becoming progressively weaker toward segment IV (Fig. 6.11). Segment V rounded in cross-section, almost entirely acarinate except for subtle vestiges of ventral lateral and ventral median carinae. Intercarinal spaces coriaceous, with vestiges of minute granules on I. Dorsal median furrow undefined on I-II, wide and shallow on III-IV, narrow and shallow on V (Figs. 3d and 6.11, 6.16).

Telson. Vesicle slightly elongated (length/width ratio $=1.90$, $\mathrm{depth} /$ width ratio $=1.0$ ) and coriaceous, with ventromedian carinae vestigial but progressively stronger distally to the subaculear tubercle, which is very small, widely conical and somewhat distant from the base of aculeus, which is shorter than vesicle and moderately curved (Figs. 3e-g and 6.21).

Female description and comparison with males. Sexual dimorphism is very well marked (Fig. 1). Females differ from males as follows: color pattern both darker and more contrasting. Tergite VII remarkably wider, with anterior margin concave and pale immaculate (Figs. 1 and 4a). Pedipalps shorter, less slender and more strongly carinate, with bulkier hand with length/width ratio $1.88 \pm 0.20$ in females $(n=7)$ vs. $2.20 \pm 0.12$ in males ( $n=7$ ) (Figs.1, 2i, j and 4b, c). Pectines comparatively smaller, with lower tooth counts: $22-25(n=14)$, mode 23 in females vs. $24-26$, mode 25 in males $(n=14)$; basal plate with anterior margin almost straight, but posterior margin widely convex (Figs. 3c, 4d and 7). Metasoma shorter and more strongly carinate; segment V length/width ratio $2.48 \pm 0.14$ in females $(n=7)$
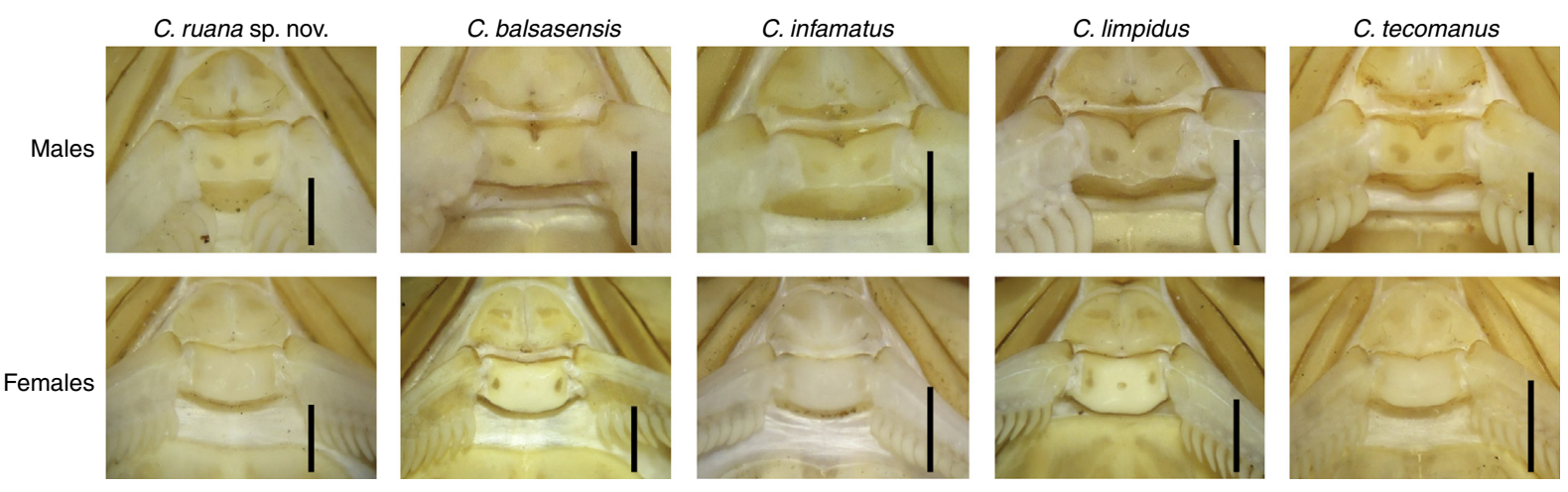

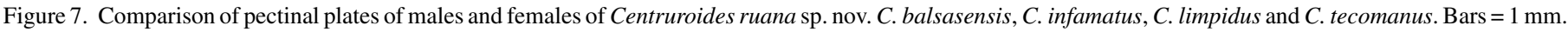


Table 4

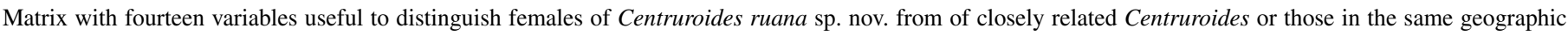
region.

\begin{tabular}{|c|c|c|c|c|c|c|c|}
\hline \multirow{2}{*}{$\begin{array}{l}\text { Females } \\
\text { Variable }\end{array}$} & \multicolumn{7}{|c|}{ Mean $( \pm \mathrm{SD})$} \\
\hline & C. ruana sp. nov. & C. infamatus & C. balsasensis & C. limpidus & C. tecomanus & Value $X^{2}$ & Prob. \\
\hline Pectinal tooth count & $22-25($ mode $=23)$ & $20-24($ mode $=21)$ & $25-28($ mode $=25)$ & $20-23($ mode $=22)$ & $20-24(\operatorname{mode}=21)$ & & \\
\hline $\begin{array}{l}\text { Metasomal segment V/III } \\
\text { length ratio }\end{array}$ & $1.24( \pm 0.03) \mathrm{A}$ & $1.25( \pm 0.03) \mathrm{A}$ & $1.17( \pm 0.03) \mathrm{B}$ & $1.17( \pm 0.01) \mathrm{B}$ & $1.16( \pm 0.02) \mathrm{B}$ & 22.2264 & 0.0002 \\
\hline $\begin{array}{l}\text { Metasomal segment } \\
\text { V/pedipalp hand length } \\
\text { ratio }\end{array}$ & $1.56( \pm 0.17) \mathrm{B}$ & $1.66( \pm 0.17) \mathrm{A}$ & $0.72( \pm 0.02) \mathrm{C}$ & $0.72( \pm 0.01) \mathrm{C}$ & $0.70( \pm 0.03) \mathrm{C}$ & 25.0407 & $<0.0001$ \\
\hline Vesicle length/width ratio & $1.61( \pm 0.03) \mathrm{C}$ & $1.46( \pm 0.05) \mathrm{D}$ & $1.80( \pm 0.05) \mathrm{A}$ & $1.69( \pm 0.06) \mathrm{B}$ & $1.58( \pm 0.10) \mathrm{C}$ & 25.4177 & $<0.0001$ \\
\hline $\begin{array}{l}\text { Metasomal segment V/IV } \\
\text { length ratio }\end{array}$ & $1.15( \pm 0.01) \mathrm{B}$ & $1.19( \pm 0.01) \mathrm{A}$ & $1.16( \pm 0.02) \mathrm{B}$ & $1.15( \pm 0.01) \mathrm{B}$ & $1.14( \pm 0.01) \mathrm{B}$ & 13.2023 & 0.0103 \\
\hline $\begin{array}{l}\text { Metasomal segment } \\
\text { I/pedipalp hand length ratio }\end{array}$ & $1.75( \pm 0.04) \mathrm{C}$ & $1.97( \pm 0.07) \mathrm{A}$ & $1.88( \pm 0.04) \mathrm{B}$ & $1.76( \pm 0.02) \mathrm{C}$ & $1.82( \pm 0.11) \mathrm{BC}$ & 20.3761 & 0.0004 \\
\hline $\begin{array}{l}\text { Metasomal segment } \\
\text { IV/vesicle length ratio }\end{array}$ & $0.98( \pm 0.10) \mathrm{B}$ & $1.06( \pm 0.05) \mathrm{A}$ & $0.49( \pm 0.01) \mathrm{C}$ & $0.49( \pm 0.01) \mathrm{C}$ & $0.48( \pm 0.02) \mathrm{C}$ & 24.5861 & $<0.0001$ \\
\hline $\begin{array}{l}\text { Metasomal segment } \\
\text { V/carapace length ratio }\end{array}$ & $1.11( \pm 0.01) \mathrm{C}$ & $1.22( \pm 0.05) \mathrm{B}$ & $1.22( \pm 0.02) \mathrm{B}$ & $1.19( \pm 0.02) \mathrm{B}$ & $1.27( \pm 0.03) \mathrm{A}$ & 24.1809 & $<0.0001$ \\
\hline $\begin{array}{l}\text { Metasomal segment } \mathrm{V} / \text { telson } \\
\text { vesicle length ratio }\end{array}$ & $2.02( \pm 0.03) \mathrm{C}$ & $2.34( \pm 0.10) \mathrm{A}$ & $2.18( \pm 0.03) \mathrm{B}$ & $2.02( \pm 0.03) \mathrm{C}$ & $2.09( \pm 0.13) \mathrm{C}$ & 21.455 & 0.0003 \\
\hline $\begin{array}{l}\text { Pedipalp patella } \\
\text { length/pedipalp hand } \\
\text { length ratio }\end{array}$ & $1.42( \pm 0.05) \mathrm{A}$ & $1.40( \pm 0.04) \mathrm{A}$ & $0.61( \pm 0.02) \mathrm{B}$ & $0.63( \pm 0.01) \mathrm{B}$ & $0.60( \pm 0.03) \mathrm{B}$ & 24.6967 & $<0.0001$ \\
\hline $\begin{array}{l}\text { Metasomal segment I } \\
\text { length/width ratio }\end{array}$ & $1.39( \pm 0.06) \mathrm{C}$ & $1.49( \pm 0.07) \mathrm{B}$ & $1.56( \pm 0.04) \mathrm{A}$ & $1.48( \pm 0.02) \mathrm{B}$ & $1.50( \pm 0.03) \mathrm{B}$ & 18.7513 & 0.0009 \\
\hline $\begin{array}{l}\text { Metasomal segment II } \\
\text { length/width ratio }\end{array}$ & $1.75( \pm 0.06) \mathrm{C}$ & $1.84( \pm 0.07) \mathrm{B}$ & $1.95( \pm 0.05) \mathrm{A}$ & $1.82( \pm 0.05) \mathrm{BC}$ & $1.83( \pm 0.09) \mathrm{B}$ & 16.3185 & $<0.0026$ \\
\hline $\begin{array}{l}\text { Pedipalp movable } \\
\text { finger/pedipalp hand length } \\
\text { ratio }\end{array}$ & $1.44( \pm 0.03) \mathrm{A}$ & $1.47( \pm 0.06) \mathrm{A}$ & $0.68( \pm 0.01) \mathrm{B}$ & $0.67( \pm 0.01) \mathrm{B}$ & $0.65( \pm 0.04) \mathrm{B}$ & 24.8859 & $<0.0001$ \\
\hline $\begin{array}{l}\text { Pedipalp fixed finger/pedipalp } \\
\text { hand length ratio }\end{array}$ & $1.21( \pm 0.05) \mathrm{A}$ & $1.21( \pm 0.05) \mathrm{A}$ & $0.60( \pm 0.02) \mathrm{B}$ & $0.59( \pm 0.01) \mathrm{BC}$ & $0.56( \pm 0.04) \mathrm{C}$ & 24.7901 & $<0.0001$ \\
\hline
\end{tabular}

vs. $3.46 \pm 0.29$ in males $(n=7)$ (Figs. $1,3 \mathrm{~d}, 4 \mathrm{e}$ and 6.11). Telson vesicle shorter and rounder: length/width ratio $1.62 \pm 0.02$ in females $(n=7)$ vs. $2.02 \pm 0.04(n=7)$ in males; subaculear tubercle stronger, aculeus longer, sharper and shallowly curved (Figs. 3e-g and 4f).

Variation. Base color varies from yellow to ochre in both sexes (Fig. 1). Spotted pattern of juvenile instars is both darker and denser, especially on pedipalps; some juveniles also have lateral and ventral surfaces of metasoma very intensely spotted. The subaculear tubercle is vestigial in some adult females, but it is strong, slender and somewhat spinoid in all juveniles.

C. ruana sp. nov. are scorpions of medium to moderately large adult size for the genus, total body length (including telson) 63.0-70.7 $(66.8 \pm 1.5, n=7)$ in males, 59.1-62.0 (60.8 \pm 1.0 , $n=7)$ in females. Carapace length of 5.7-6.4 $(6.0 \pm 0.4, n=7)$ in males, 6.1-6.5 (6.3 $\pm 0.3, n=7)$ in females. Pedipalps longer and more slender than similar species (length femur and patella: 5.9-6.6 (6.2 $\pm 0.4, n=7), 6.4-7.2(6.8 \pm 0.4, n=7)$ in males and 5.4-6.0 (5.7 $\pm 0.3, n=7), 6.1-6.8(6.4 \pm 0.4, n=7)$ in females, respectively. Hand relatively longer in females (fixed finger/hand length ratio: $1.1-1.3[1.2 \pm 0.1, n=7]$ in males, $1.4-1.5$ $[1.2 \pm 0.03, n=7]$ in females). Movable finger/hand length ratio: $1.1-1.3(1.2 \pm 0.2, n=7)$ in males, $1.4-1.5(1.4 \pm 0.03, n=7)$ in females. Basal plate of pectines width/length ratio: 1.5-2.0
$(1.7 \pm 1.3, n=7)$ in males, $1.8-2.0(1.9 \pm 0.08, n=7)$ in females. Total length/metasoma length ratio: $1.78-1.83(1.8 \pm 0.02$, $n=7)$ in males, $2.05-2.17(2.1 \pm 0.05, n=7)$ in females. Number of pectinal teeth is $24-26$ (mode $=25 ; n=14$ ) in males and $22-25$ (mode $=23 ; n=14$ ) in females.

\section{Taxonomic summary}

Type data. Adult male holotype (CNAN-T0874), 1 adult male and 2 adult female paratypes (CNAN-T0875), 6 adult male and 6 adult female paratypes (CAFBUM 2015-0503), all with the following data: Mexico: Michoacán: Buenavista Municipality: Felipe Carrillo Puerto (= La Ruana), Ejido "Santa Rita", $19.1224^{\circ} \mathrm{N}, 102.7117^{\circ} \mathrm{W}$; 7.III.2013; coll. L. Gaona E.

\section{Other material examined}

Two adult males and 4 adult females (CAFBUM) with the same data as the types, except collected on 6.XII.2014. One adult female (CAFBUM) from Michoacán: Apatzingán de la Constitución Municipality: Las Colonias: Cenobio Moreno; $19.0933^{\circ} \mathrm{N}, 102.5014^{\circ} \mathrm{W}$; 1.VI.2012; coll. J. Ponce, A. Quijano, L. Echeverría. One adult female (CAFBUM) from Michoacán: Apatzingán de la Constitución Municipality: Panteón Municipal; $19.0731^{\circ} \mathrm{N}, 102.3692^{\circ} \mathrm{W}$; 2.XI.2013; coll. J. Baldazo. 

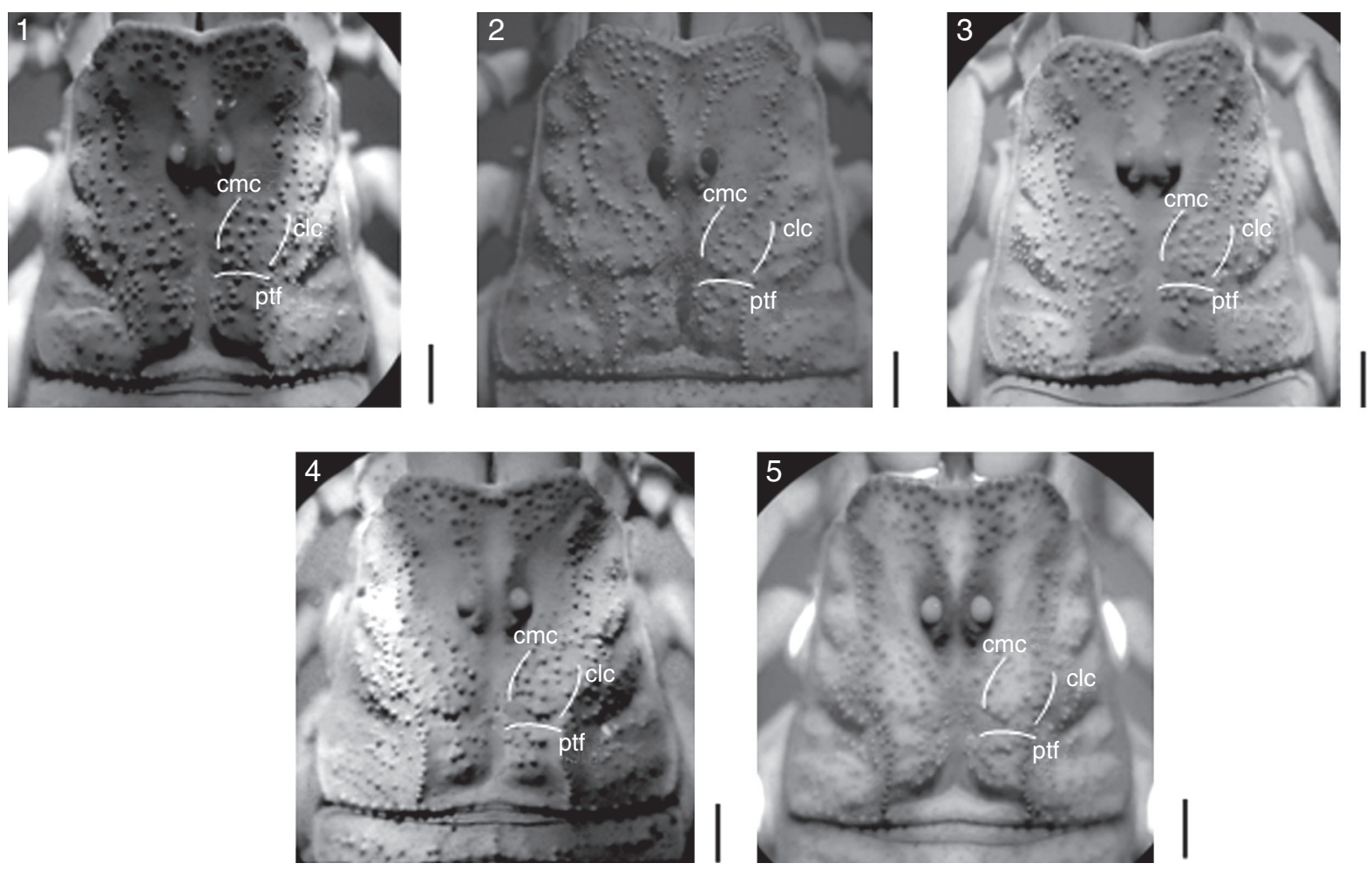

Figure 8. Granulation comparison of carapace between: (1) Centruroides ruana sp. nov.; (2) C. balsasensis; (3) C. infamatus; (4) C. limpidus, and (5) C. tecomanus. Central median carinae $(\mathrm{cmc})$, central lateral carinae (clc), and posterior transverse furrow $(\mathrm{ptf})$. Bars $=1 \mathrm{~mm}$.

\section{Etymology}

The specific epithet is an indeclinable noun in apposition, taken directly from the unofficial but better-known name of the type locality: Felipe Carrillo Puerto (= La Ruana).

\section{Distribution}

Only known from 2 nearby localities of the lowland Balsas Basin, in west-central Michoacán (Fig. 4). Both localities are in the Apatzingán Valley (Fig. 5).

\section{Remarks}

The new species is similar in size and coloration to Centruroides infamatus (Fig. 6), and both taxa are also geographically close. The latter can be distinguished by the less slender pedipalps, with femur, patella and chela shorter; hand of pedipalp slightly less elongated; metasoma and telson longer (Table 2). Also, metasoma with dorsal lateral, lateral supramedian, and lateral inframedian carinae less developed and granular to crenulated except the dorsal laterals, which are finely serrated and even denticulate (Fig. 6.11, 6.14). The basal plate of pectines in males of $C$. infamatus with the anteromedian notch shallow and the anterior margin not lobulated, in females with the anterior margin concave but not notched and posterior margin clearly recurved (Fig. 7).

Another species that is morphologically similar and found in the same geographic region is C. balsasensis (Fig. 6), which can be differentiated from $C$. ruana sp. nov. by the coloration paler and less densely patterned, the color pattern on carapace and tergites (Fig. 6), and the carapace with anterior margin noticeably notched, convex, with granules that are denser on the median part. General habitus of $C$. balsasensis slightly less slender, including pedipalps with more robust chelae (obvious in the fingers/manus length ratio) (Tables 3 and 4); basal pectinal plate of males of $C$. balsasensis with anterior margin almost straight and not lobulated; in females the anterior margin is clearly concave and the posterior margin is strongly convex. Males of $C$. balsasensis with subaculear tubercle markedly stronger (Fig. 7).

Centruroides limpidus is more distantly related to C. ruana sp. nov. based on morphological criteria, but both species are sympatric in the Felipe Carrillo Puerto area. Although $C$. limpidus is present in very low abundance here, it is easy to recognized by the carapace color pattern, which has 2 pairs of thin, longitudinal, sub parallel blackish stripes: 1 lateral across the entire carapace (Fig. 6.21, 6.24), and 1 submedian that extends shortly behind the ocular tubercle (Fig. 6.1, 6.2), leaving most part of the surface without pigment. Other differences are morphometric features (for measurements see Tables 3 and 4).

Centruroides tecomanus is another species that could be confused with the new species herein described (Figs. 6 and 7), owing to its general appearance; however, in addition to the morphometric differences (Tables 3 and 4), the coastal distribution of this species; the constant color pattern of its carapace, always with 4 thin and well defined dark lines (Fig. 6.1, 6.5); and the subaculear tubercle well developed and generally with its point oriented toward the point of aculeus (Ponce-Saavedra et al., 2009) (Fig. 6.21, 6.25) are enough to distinguish this species from the newly described one. 
a
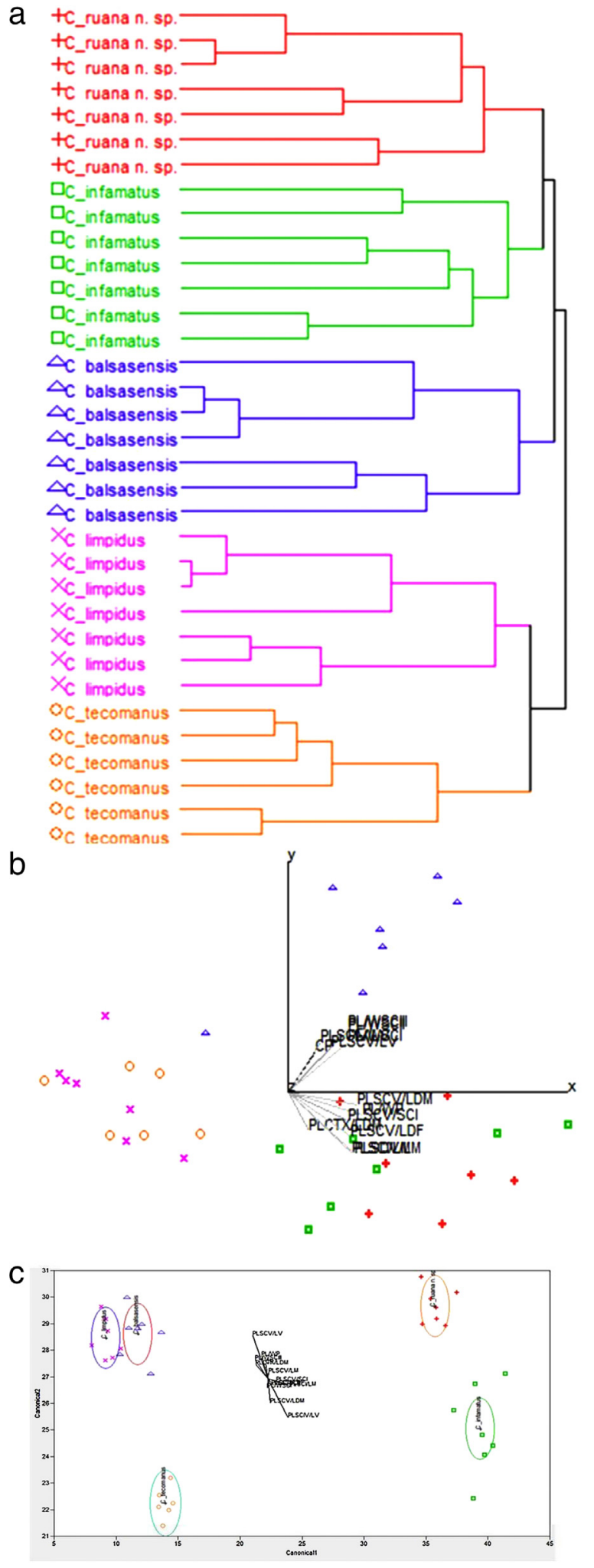

Males
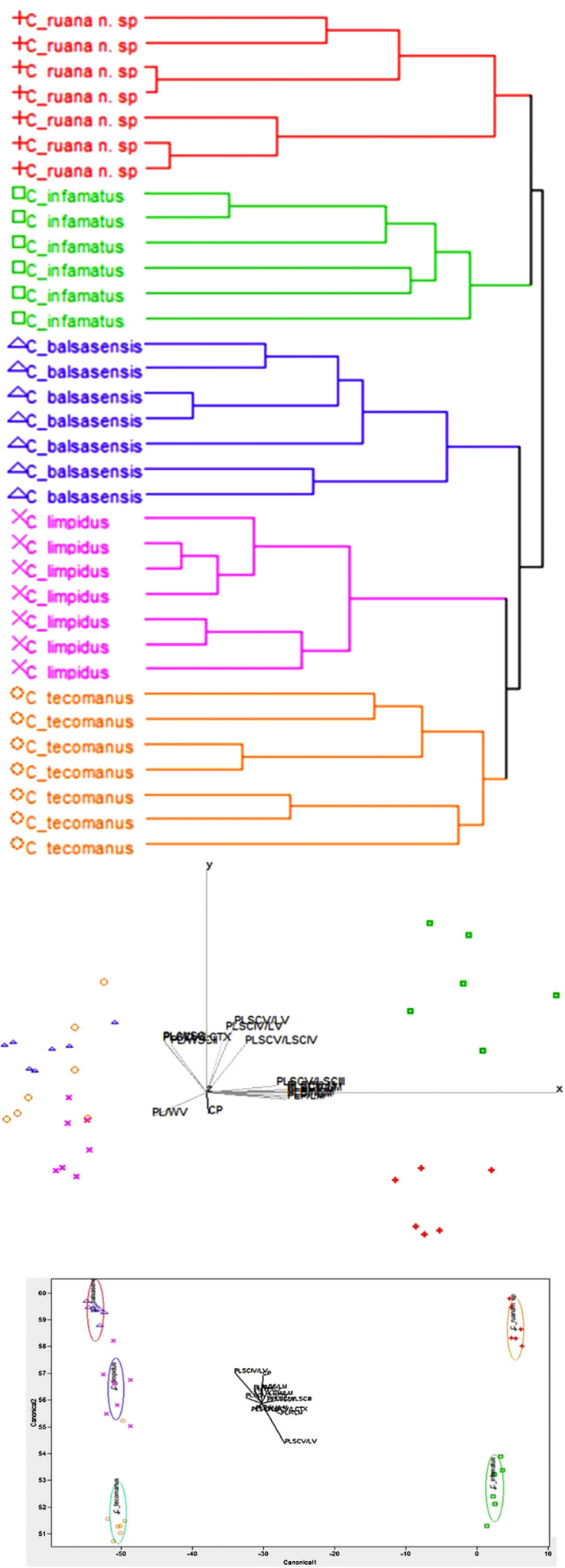

Females

Figure 9. (a) clustering plots obtained with Ward's method and standardized data; (b) ordination graphics of 2 first principal components of PCA, and (c) graphics obtained from canonical discriminant analysis. All analyses were made with 13 variables in females and 14 in males. Centruroides ruana sp. nov. (plus symbol), $C$. infamatus (square), C. balsasensis (triangle), C. limpidus (letter X), C. tecomanus (circle). 
Additionally we made a comparison of granulation pattern of the carapace of $C$. ruana sp. nov., C. balsasensis, $C$. infamatus, $C$. limpidus, and $C$. tecomanus using images in UV light. Differences in the patterns of granulation of central median carinae (cmc) and central lateral carinae (clc) as well as in the granulation located above the posterior transverse furrow (ptf) can be appreciated between species (Fig. 8).

\section{Morphometric analysis}

A morphometric statistical analysis was conducted in order to reinforce the diagnostic comparison between $C$. ruana sp. nov., C. balsasensis, C. infamatus, C. limpidus, and $C$. tecomanus. As a whole, 54 variables were included: 28 measurements, 25 derived proportional ratios and a meristic count. Matrices were constructed using the following labels for each taxon: C_ruana, C_balsasensis, C_infamatus, C_limpidus, and C_tecomanus. A Cluster Analysis (CA) was performed using Euclidean distances, standardized data and Ward's Minimum Variance Method followed by a Principal Component Analysis (PCA). The results revealed that specimens previously assigned to a particular taxon, consistently clustered together and isolated from others, forming groups of defined species (Fig. 9a).

In order to reduce the number of variables supporting the species distinction and to discard any potential effect of size among the 3 taxa (a clean-up process), all matrices were depurated by eliminating those variables found to be highly correlated or with little information. The former are simple redundant, while the latter represent variation which is very poorly explained through the PCA. As outcomes, a thirteen variable matrix was obtained for males and another with fourteen for females (Tables 3 and 4).

Using these variables and running separate analyses for both males and females, a second CA was calculated, and again, specimens of each previously identified taxon clustered together and were separated from all other species (Fig. 9a). A subsequent PCA applied to these matrices yielded $85.67 \%$ and $87.55 \%$ of explained variation in 3 principal components for both males and females, respectively (Fig. 9b). Further, a canonical discriminant analysis (CDA) demonstrated that the morphometric distinction of all species is adequate (Fig. 9c): tests such as Wilks' Lambda, Pillai's Trace, Hotelling-Lawley and Roy's Max Root, all proved significant $(p<0.05)$ and yielded null misclassifications. In males (Table 3 ), thirteen variables were found to present univariate significant statistical difference $(p<0.05)$. In females (Table 4$)$, the number of such variables was fourteen $(p<0.05)$.

The morphologic and morphometric data support C. ruana sp. nov. as a valid species, clearly distinct from the morphologically similar C. balsasensis and $C$. infamatus and from $C$. limpidus, which is the species found closest geographically. The difference with $C$. tecomanus was also clear. The overall resemblance in the habitus among $C$. limpidus and $C$. balsasensis and $C$. ruana makes it very likely that this new species is actually more widespread across the Balsas Basin, but has been misidentified in collections.

\section{Acknowledgements}

This paper forms part of the first author's $\mathrm{PhD}$ thesis, a study that was funded through a grant from the Consejo Nacional de Ciencia y Tecnología, Mexico. We are grateful to the Coordinación de la Investigación Científica of Universidad Michoacana de San Nicolás de Hidalgo for the support for field work; to Lizbeth Gaona Escamilla and M.C. José Guadalupe Baldazo Monsivaiz for collecting and donating most specimens of the new species; to Dr. Rolando Teruel for the thorough review of the manuscript, the English translation of the final draft, and his valuable and helpful comments. We are grateful to Dr. Oscar F. Francke for his valuable comments and Dr. Robert W. Jones for the review of the English final manuscript.

\section{References}

Acosta, L. E., Candido, D. M., Buckup, E. H., \& Brescovit, A. D. (2008) Description of Zabius gaucho (Scorpiones Buthidae), a new species from southern Brazil, with an update about the generic diagnosis. The Journal of Arachnology, 36, 491-501.

Armas, L. F. de. (2009). Sinopsis de los escorpiones antillanos. La Habana: Editorial Ciencia y Técnica.

Fet, V., \& Lowe, G. (2000). Family Buthidae C. L. Koch, 1837. In V. Fet, W. D. Sissom, G. Lowe, \& M. E. Braunwalder (Eds.), Catalog of the scorpions of the World (1758-1998) (pp. 54-286). New York: The New York Entomological Society.

Francke, O. F. (1977). Scorpions of the genus Diplocentrus Peters from Oaxaca, México. The Journal of Arachnology, 4, 145-200.

Francke, O. F., Teruel, R., \& Santibañez-López, C. E. (2014). A new genus and a new species of scorpion (Scorpiones: Buthidae) from southeastern Mexico. Journal of Arachnology, 42, 220-232.

Hoffmann, C. C. (1932). Monografías para la Entomología Médica de México. 2. Los escorpiones de México. Segunda parte: Buthidae. Anales del Instituto de Biología de la Universidad Nacional Autónoma de México, Serie Zoología, 3, 283-361.

JMP v. 6.0. (2005). SAS Institute Inc., Cary, NC, 1989-2007. NC, USA.

Ozkan, O., Adiguzel, Z., \& Kar, S. (2006). Parametric values of Androctonus crassicauda (Oliver, 1807) (Scorpiones: Buthidae) from Turkey. Journal of Venomous Animal and Toxins Including Tropical Diseases, 12, 549-559.

Ponce-Saavedra, J., \& Francke, O. F. (2004). Una nueva especie de alacrán del género Centruroides Marx (1890) (Scorpiones: Buthidae) de la Depresión del Balsas, México. Acta Zoológica Mexicana, 20, 221-232.

Ponce-Saavedra, J., \& Francke, O. F. (2009). Descripción de una especie nueva de alacrán con importancia médica del género Centruroides (Scorpiones: Buthidae) del Estado de Colima, México. Revista Mexicana de Biodiversidad, 80, 647-658.

Ponce-Saavedra, J., \& Francke, O. F. (2011a). Nueva especie de alacrán del género Centruroides (Scorpiones, Buthidae) del Estado de Jalisco, México. Revista Mexicana de Biodiversidad, 82, 465-474.

Ponce-Saavedra, J., \& Francke, O. F. (2011b). Especie nueva de alacrán del género Centruroides (Scorpiones: Buthidae) de la costa del Estado de Jalisco, México. Revista Mexicana de Biodiversidad, 82, 1163-1175.

Ponce-Saavedra, J., \& Francke, O. F. (2013a). Actualización taxonómica sobre alacranes del Centro Occidente de México. Dugesiana, 20, 73-79.

Ponce-Saavedra, J., \& Francke, O. F. (2013b). El género Centruroides Marx 1890 (Scorpiones: Buthidae) y su importancia médica en el estado de Michoacán, México. Entomología Mexicana, 12, 811-816.

Ponce-Saavedra, J., Francke, O. F., Cano-Camacho, H., \& Hernández-Calderón, E. (2009). Evidencias morfológicas y moleculares que validan como especie a Centruroides tecomanus (Scorpiones: Buthidae). Revista Mexicana de Biodiversidad, 80, 71-84. 
Ponce-Saavedra, J., Martínez-Rodríguez, I., \& Quijano-Ravell, A. F. (2015). Alacranes de importancia médica en la Depresión del Balsas. Entomología Mexicana, 2, 66-70.

Rein, J. O. (2015). The Scorpion files. http://www.ntnu.no/ub/scorpion-files/

Santibáñez-López, C. E., \& Ponce-Saavedra, J. (2009). A new species of Centruroides (Scorpiones: Buthidae) from the northern mountain range of Oaxaca, Mexico. Revista Mexicana de Biodiversidad, 80, 321-331.
Stahnke, H. L. (1970). Scorpion nomenclature and mensuration. Entomological News, 81, 297-316.

Teruel, R., Kovarik, F., Baldazo-Monsivais, J. G., \& Hoferek, D. (2015). A new species of Centruroides of the "nigrovariatus" group (Scorpiones: Buthidae) from southern Mexico. Revista Ibérica de Aracnología, 26, 3-14. 